International Journal of

BioScience and Applications

\title{
Correlation analysis between Hypertension and Dietary Supplements intake in Koreans: Report Based on Korean National Health and Nutritional Examination Survey (KNHANES)
}

\author{
Hae-Ryoung Park \\ Department of General Education, Kwangju Women's University, Republic of Korea
}

\begin{abstract}
${ }^{1}$
Background/Objectives: The purpose of this study was to provide basic data for preparing an appropriate and correct dietary supplement management program by examining the correlation between hypertension and dietary supplements intake. Methods/Statistical analysis: Using the 2019 KNHANES VIII-1 data, the prevalence of hypertension and the intake of dietary supplements for 2 weeks in the past year were statistically analyzed by age, sex, house income and education level. Findings: High blood pressure was the highest with ' Yes ' at $18.9 \%$, and ' No ' at $1.0 \%$. A person with a 'yes' of hypertension took dietary supplements for at least 2 weeks in the past year (58.6\%). Improvements/Applications: Based on this study, we intend to use it as a guideline for follow-up studies on the High Blood Pressure and whether dietary supplements are consumed according to the guidelines of education on the recognition of the benefits and harms of diseases.
\end{abstract}

\section{Index Terms}

Hypertension, Dietary supplements, Korea National Health and Nutrition Examination Survey, High Blood Pressure, Subjective Body Recognition

\footnotetext{
Corresponding author : Hae-Ryoung Park

hrpark@kwu.ac.kr

- Manuscript received July 15, 2021.

- Revised August 10, 2021 ; Accepted September 1, 2021.

- Date of publication September 30, 2021

(c) The Academic Society of Convergence Science Inc.

2619-8363 @ 2021 IJBSA. Personal use is permitted, but republication/redistribution requires IJBSA permission.
} 


\section{INTRODUCTION}

In 1994, Americans enacted the Dietary Supplement Health and Education Act, DSHEA). A dietary supplement or nutritional supplement refers to a product manufactured to be consumed in the form of pills, capsules, powders, or liquids as a compound to increase the amount of nutrients or consumption extracted from food [1]. One or more dietary ingredients include vitamins, minerals, herbs or other plants, amino acids and other substances. These dietary ingredients indicate products for supplementing the ingredients. And it must be labeled as a dietary supplement on the front panel [1]. Food supplements were intended to correct nutritional deficiencies, maintain adequate intake of certain nutrients, or support certain physiological functions. As it was not a drug, it cannot exert pharmacological, immunological or metabolic action. Therefore, it was regulated in the EU that it was not intended to treat or prevent human diseases or to modify physiological functions.

Therefore, food supplements were regulated as food in the EU. This law limits the vitamins and minerals that can be used in the manufacture of dietary supplements and the raw materials used as their sources. For ingredients other than vitamins and minerals, the European Commission has established strict rules to protect consumers from potential health risks, maintains a list of substances known or suspected of having adverse health effects, and controls the use of food supplements. [2]. According to the results of a study 10 years ago, women took more vitamin and mineral supplements than men. For the age group of 40-64 years, the higher the education level, the larger the city dweller, the higher the monthly income, the more tended to consume supplements [3]. Dietary supplements contain substances other than essential nutrients and have been used not to correct deficiencies, but to increase the total dietary intake of some foods or plants that can enhance a person's health [4].

The purpose of this study was to investigate whether food supplements are adequately consumed in an effort to improve physiological functions while improving nutritional deficiencies and increasing or maintaining intake of specific nutrients.

In addition, since it was not a drug, it was intended to find out the amount of food supplements used by people with diseases, to prevent misuse of food supplements, and to suggest new alternatives to healthy physical activity.

\section{RESEARCH METHOD}

\section{A. Investigation method}

KNHANES VIII-1 (Korea Centers for Disease Control and Prevention, IRB No: 2018-01-03-C-A) collected survey data with the consent of the participants according to the survey items and purpose. The purpose of the Korea National Health and Nutrition Examination Survey was to calculate the national level of health, health behavior, and food and nutrition intake at the national level and produce reliable statistics. It was to be used as basic data for health policy such as development [5].

\section{B. Research design}

This study was a descriptive research study in which secondary analysis of data from the 8th Korea National Health and Nutrition Examination Survey (KNHANES VIII-1) was conducted to identify the factors affecting people who took dietary supplements for 2 weeks or more for one year in Korea and those with hypertension. In the case of taking dietary supplements, only the contents consumed one day before the survey during the food intake survey up to the 7 th year 2 (2017) were investigated [5].

\section{B. General Characteristics}

For general characteristics in this study, gender was 'male' and 'female', and the age was reclassified into '20-29', '30-39', '40-49', '50-59', '60-69', '70-79', and '>80'. Education level was classified into ' $<$ Middle school', 'middle school', 'high school', and 
' $\geq$ University'. As for house income, household income was divided into 'low', 'lower-middle', 'middlehigh', and 'high' based on income quartiles.

\section{Analysis Method}

The data were analyze the data using IBM SPSS 21.0 program. As for the statistical analysis method, crossanalysis (chi-square test) was performed to analyze the independence and relevance between the two variables. Pearson correlation coefficient was measured to find out the relationship between each variable.

\section{ReSults}

\section{A. General Characteristics}

The results regarding the general characteristics of the study subjects were as follows. The total number of participants is 8107 , and each item was the result of excluding missing values. Table 1 showed the results of the gender, age, education and house income of general characteristics of subjects were expressed through frequency analysis.

Table 1. General characteristics of subjects

\begin{tabular}{|c|c|c|c|}
\hline Characteristics & Categories & $\mathrm{N}$ & $\%$ \\
\hline gender & man & 3729 & 46.0 \\
\cline { 2 - 4 } & women & 4378 & 54.0 \\
\hline \multirow{7}{*}{ age } & $20-29$ & 749 & 9.2 \\
\cline { 2 - 4 } & $30-39$ & 985 & 12.1 \\
\cline { 2 - 4 } & $40-49$ & 1182 & 14.6 \\
\cline { 2 - 4 } & $50-59$ & 1245 & 15.4 \\
\cline { 2 - 4 } & $60-69$ & 1186 & 14.6 \\
\cline { 2 - 4 } & $70-79$ & 846 & 10.4 \\
\cline { 2 - 4 } & $>80$ & 349 & 4.3 \\
\hline Education & $<$ Middle school & 2273 & 28.0 \\
\cline { 2 - 4 } & Middle school & 755 & 9.3 \\
\cline { 2 - 4 } & High school & 2011 & 24.8 \\
\cline { 2 - 4 } & $\geq$ University & 2293 & 28.3 \\
\hline House income & Low & 1076 & 13.3 \\
\cline { 2 - 4 } & Low \& middle & 1492 & 18.4 \\
\cline { 2 - 4 } & Middle & 1716 & 21.2 \\
\cline { 2 - 4 } & Middle \& high & 1936 & 23.9 \\
\cline { 2 - 4 } & High & 1847 & 22.8 \\
\hline
\end{tabular}

\section{B. Subjective Body Recognition}

Table 2 shows the comparison results according to subjective body recognition. Subjective body recognition was the highest with ' commonly' at $36.3 \%$, followed by ' slightly overweight' at $28.9 \%$. Looking at the subjective body recognition rate of those who answered that they took dietary supplements for 2 weeks or more in the past year, 'commonly ' $39.4 \%$, ' slightly overweight ' $30.0 \%$ '. The result of correlation analysis was -.045 , which was a statistically significant probability as shown in Table 3.

Table 2. Frequency rate of subjective body recognition

\begin{tabular}{|c|c|r|r|}
\hline Characteristics & Categories & \multicolumn{1}{|c|}{$\mathrm{N}$} & \multicolumn{1}{c|}{$\%$} \\
\hline $\begin{array}{c}\text { Subjective } \\
\text { Body } \\
\text { Recognition }\end{array}$ & very skinny & 346 & 4.3 \\
\cline { 2 - 4 } & a little skinny & 1001 & 12.3 \\
\cline { 2 - 4 } & commonly & 2939 & 36.3 \\
\cline { 2 - 4 } & $\begin{array}{c}\text { slightly } \\
\text { overweight }\end{array}$ & 2342 & 28.9 \\
\cline { 2 - 4 } & very obese & 626 & 7.7 \\
\cline { 2 - 4 } & Unmatched & 354 & 4.4 \\
\cline { 2 - 4 } & Unknown & 98 & 1.2 \\
\cline { 2 - 4 } & Total & 7706 & 95.1 \\
\hline
\end{tabular}

Table 3. Whether you have taken dietary supplements for 2 weeks or more in the past year according to subjective body recognition

\begin{tabular}{|l|c|c|c|c|c|}
\hline \multirow{4}{*}{ Characteristics } & Categories & \multicolumn{4}{|c|}{ Dietary Supplements } \\
\cline { 3 - 6 } & & \multicolumn{2}{|c|}{ Yes } & \multicolumn{2}{|c|}{ No } \\
\cline { 3 - 6 } & $\mathrm{N}$ & $\%$ & $\mathrm{~N}$ & $\%$ \\
\hline $\begin{array}{l}\text { Subjective } \\
\text { body } \\
\text { recognition }\end{array}$ & $\begin{array}{c}\text { very } \\
\text { skinny }\end{array}$ & 147 & 3.7 & 158 & 5.7 \\
\cline { 2 - 6 } & $\begin{array}{c}\text { a little } \\
\text { skinny }\end{array}$ & 495 & 12.5 & 382 & 13.7 \\
\cline { 2 - 6 } & commonly & 1558 & 39.4 & 1034 & 37.0 \\
\cline { 2 - 6 } & $\begin{array}{c}\text { slightly } \\
\text { overweight }\end{array}$ & 1186 & 30.0 & 846 & 30.3 \\
\cline { 2 - 6 } & very obese & 294 & 7.4 & 245 & 8.8 \\
\cline { 2 - 6 } & Unmatched & 247 & 6.2 & 91 & 3.3 \\
\cline { 2 - 6 } & Unknown & 30 & 0.8 & 36 & 1.3 \\
\cline { 2 - 6 } & Total & 3957 & 100 & 2792 & 100 \\
\hline$\chi^{2}(\mathrm{p})$ & \multicolumn{4}{|c|}{$-.045(.000) * *$} \\
\hline $\mathrm{p}^{* *<.01}$ & & & & \\
\hline
\end{tabular}

\section{Weight control for 1 year}

Table 4 shows the comparison results according to weight control for 1 year. Weight control for 1 year was the highest with ' weight loss efforts ' at $33.7 \%$, followed by ' I've never tried to control my weight ' at $32.5 \%$. 
Table 4. Frequency rate of weight control for 1 year

\begin{tabular}{|c|c|c|c|}
\hline Characteristics & Categories & $\mathrm{N}$ & $\%$ \\
\hline $\begin{array}{c}\text { Weight control for } \\
\text { 1 year }\end{array}$ & $\begin{array}{c}\text { weight loss } \\
\text { efforts }\end{array}$ & $\mathbf{2 7 2 9}$ & $\mathbf{3 3 . 7}$ \\
\cline { 2 - 4 } & $\begin{array}{c}\text { weight } \\
\text { maintenance } \\
\text { effort }\end{array}$ & 1364 & 16.8 \\
\cline { 2 - 4 } & $\begin{array}{c}\text { weight gain } \\
\text { effort }\end{array}$ & 528 & 6.5 \\
\cline { 2 - 4 } & $\begin{array}{c}\text { I've never tried } \\
\text { to control my } \\
\text { weight }\end{array}$ & 2634 & 32.5 \\
\cline { 2 - 4 } & Unmatched & 354 & 4.4 \\
\cline { 2 - 4 } & Unknown & 97 & 1.2 \\
\cline { 2 - 4 } & Total & 7706 & 95.1 \\
\hline
\end{tabular}

\section{Weight control method: health functional food}

Table 5 shows the comparison results according to Weight control method: health functional food. Weight control method: health functional food was the highest with ' No ' at $45.9 \%$, followed by ' Unmatched ' at $43.4 \%$.

Table 5. Frequency rate of weight control method in health functional food

\begin{tabular}{|c|c|c|c|}
\hline Characteristics & Categories & $\mathrm{N}$ & $\%$ \\
\hline \multirow{2}{*}{\begin{tabular}{c} 
Weight \\
control \\
method: \\
health \\
\cline { 2 - 4 } $\begin{array}{c}\text { functional } \\
\text { food }\end{array}$
\end{tabular}} & No & 3720 & 45.9 \\
\cline { 2 - 4 } & Unmatched & 372 & 4.6 \\
\cline { 2 - 4 } & Unknown & 98 & 43.4 \\
\hline
\end{tabular}

Table 6. Correlation between whether you have taken dieta ry supplements for 2 weeks or more in the past year and weight control method in health functional food

\begin{tabular}{|l|c|c|c|c|c|}
\hline \multirow{2}{*}{ Characteristics } & \multirow{2}{*}{ Categories } & \multicolumn{4}{|c|}{ Dietary Supplements } \\
\cline { 3 - 6 } & & \multicolumn{2}{|c|}{ Yes } & \multicolumn{2}{|c|}{ No } \\
\cline { 3 - 6 } & $\mathrm{N}$ & $\%$ & $\mathrm{~N}$ & $\%$ \\
\hline \multirow{2}{*}{$\begin{array}{l}\text { Weight } \\
\text { control } \\
\text { method: } \\
\text { health } \\
\text { functional } \\
\text { food }\end{array}$} & No & 1942 & 49.1 & 1293 & 46.3 \\
\cline { 2 - 6 } & Unmatched & 1743 & 44.0 & 1394 & 49.9 \\
\cline { 2 - 6 } & Unknown & 30 & 0.8 & 36 & 1.3 \\
\cline { 2 - 6 }$\chi^{2}(\mathrm{p})$ & Total & 3235 & 100 & 2792 & 100 \\
\hline $\mathrm{p}^{* *<.01}$ & & \multicolumn{5}{|c}{$.060(.000) * *$} \\
\hline
\end{tabular}

\section{E. Hypertension}

Table 7 shows the comparison results according to hypertension. High blood pressure was the highest with ' Yes ' at $18.9 \%$, and ' No ' at $1.0 \%$. Table 8 shows a person with a 'yes' of hypertension took dietary supplements for at least 2 weeks in the past year $(58.6 \%)$.

Table 7. Frequency rate of hypertension

\begin{tabular}{|c|c|r|r|}
\hline Characteristics & Categories & \multicolumn{1}{|c|}{$\mathrm{N}$} & \multicolumn{1}{c|}{$\%$} \\
\hline Hypertension & No & 81 & 1.0 \\
\cline { 2 - 4 } & Yes & 1529 & 18.9 \\
\cline { 2 - 4 } & Unknown & 6096 & 79.1 \\
\cline { 2 - 4 } & Total & 1936 & 95.1 \\
\hline
\end{tabular}

Table 8. Relationship between high blood pressure and dietary supplements

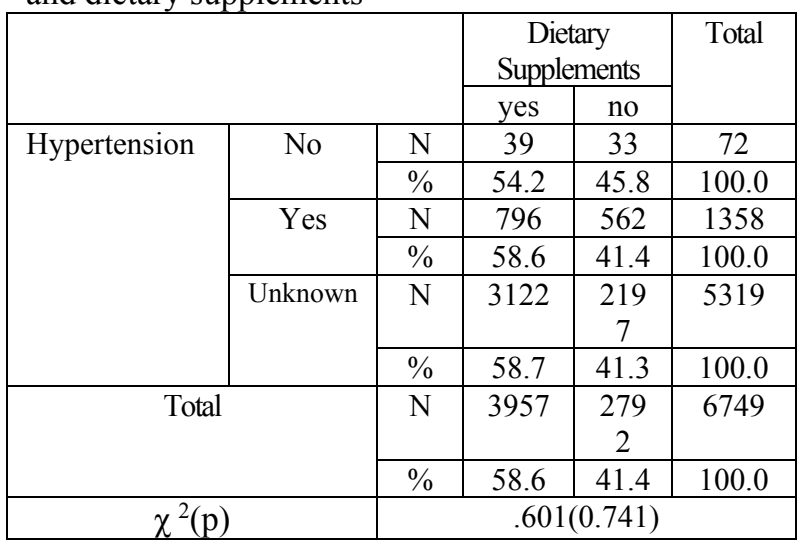

\section{CONCluSion AND Discussion}

According to the data, when controlling weight in the last year, $33.7 \%$ had experience trying to lose weight. On the other hand, $32.5 \%$ of respondents said they had never tried it.

In terms of subjective body recognition, there was no difference in the ratio between those who took dietary supplements and those who did not in the group perceived as slightly overweight. However, in terms of subjective body type perception, when looking at the ratio of those who took dietary supplements to those who did not, in the group perceived as ' very obese', there were many people who answered that they did not take dietary supplements $(8.8 \%)$. According to the results of this study, dietary supplements were not taken according to subjective body type perception.

It was found that exercise and diet reduction were the most common methods of weight control. It was found that the older people were and the more they perceived themselves as obese, the more they practiced various weight control methods, but there was no significant difference between the body type recognition groups. Among all age groups, it was found that women who perceived themselves as obese were the most likely to try diet for weight control [6].

It was found that the group taking health functional foods as a weight control method did not take dietary supplements $(6.1 \%)$. 
High blood pressure was the highest with ' Yes ' at $18.9 \%$, and ' No ' at $1.0 \%$. Not statistically significant, a person with a 'yes' of hypertension took dietary supplements for at least 2 weeks in the past year $(58.6 \%)$.

Intake of omega- 3 fats, one of the dietary supplements, did not clearly reduce total mortality and cardiovascular events. Higher omega- 3 intake did not increase the risk of cancer, but the clinical harm could not be ruled out. In other words, longchain and short-chain omega- 3 fats did not have a clear effect on total mortality, complex cardiovascular disease, or cancer [7].

This study was the result of statistical analysis on the prevalence of hypertension and dietary supplement intake. Among those who took dietary supplements for 2 weeks or more in the past year, $58.6 \%$ of those with hypertension took dietary supplements. Although it was not statistically significant between the two groups, at least those with hypertension took dietary supplements. In the future, based on this study, we intended to provide basic data on proper and correct dietary supplement intake. Also, according to the type of dietary supplement, it was intended to provide basic data for education on the recognition of the benefits and harms of diseases.

\section{REFERENCES (APA STYLE)}

[1] "Dietary Supplements: Background Information" https://web.archive.org/web/20200814221351/https:/ /ods.od.nih.gov/factsheets/DietarySupplements-

HealthProfessional/

[2] European Food Safety Authority, European Commission. 2009.

https://www.efsa.europa.eu/en/topics/topic/foodsupplements.

[3] Yeo-ok Lee, Yoon Ju Song. Sociodemographic Characteristics, Lifestyle Factors, and Nutrient Intake by Taking Vitamin/mineral Supplements. KOREAN J. FOOD CULTURE. 2010. 25(4): 480486.

[4] American Heart Association Nutrition Committee. Diet and lifestyle recommendations revision 2006: a scientific statement from the American Heart Association Nutrition Committee. Circulation. 2006;114(1):82-96.

[5] Eighth Korea National Health and Nutrition Examination Survey (KNHANES VIII-1), 2019, Korea Disease Control and Prevention Agency.

[6] Young-Suk Lim, Na-Ri Park, Su-Bin Jeon, SoYeon Jeong, Zuunnast Tserendejid, Hae-Ryun Park. Analysis of Weight Control Behaviors by Body Image Perception among Korean Women in Different Age Groups: Using the 2010 Korea National Health and Nutrition Examination Survey
Data. Korean Journal of community Nutrition. 2015; 20(2):141 150.

[7] Hooper L, Thompson RL, Harrison RA, Summerbell CD, Ness AR, Moore HJ, Worthington HV, Durrington PN, Higgins JPT, Capps NE, Riemersma RA, Ebrahim SBJ, Davey Smith G. Risks and benefits of omega-3 fats for mortality, cardiovascular disease and cancer: a systematic review. Achieves of British Med Journal. 2006;332:752-760. 